\title{
Causal Relationships between the Polar Nuclei in Double Fertilization and Interspecific Cross-incompatibility in Avena
}

\author{
1. Nishiyama ${ }^{1}$ and T. Yabuno \\ College of Agriculture, University of Osaka Prefecture, Osaka, 591 Japan
}

Received January 3, 1977

Failure of interspecific crosses is usually caused by disturbance in reproductive processes peculiar to plant species in pre- or post-fertilization. The former indicates the sequences of events from pollen germination on the stigma to union of male and female nuclei in the ovule, and the latter includes all subsequent processes leading to maturity of the seed. However, both forms of sterility have often been mixed up, partly due to incomplete observations. In general little is known about the cause of post-fertilization failure.

In connection with this subject attention was first directed to differences in seed development in reciprocal crosses between species with different numbers of chromosomes (Gairdner 1926, Gairdner and Darlington 1931, Watkins 1927, 1932, Müntzing 1930, 1933). Similar results were often found in wide crosses regardless of the chromosome numbers of the parents. Thus this type of sterility has proved to be rather general in crosses between different species and sometimes within species.

Explanations of the failure of hybrid seeds were proposed by many workers who discussed this problem from different standpoints. Main hypotheses are as follows: 1) variation of genomes in embryo: endosperm: maternal tissues from the normal 2:3:2 ratio (Müntzing 1930, 1933), or its modifications (Watkins 1927, 1932, Katayama 1933, Boyes and Thompson 1937); 2) variation in genetic 'strength' or genetic value in different species (Howard 1939, 1947, Stephens 1942, Valentine 1956, Valentine and Woodell 1963); 3) somatoplastic sterility (Brink and Cooper 1939, 1940); 4) an inharmonious interaction between male and female gametes at double fertilization (Kihara and Nishiyama 1932); 5) disturbed ratios between the amount of cytoplasm (extrachromosomalen Bestandteil) and the number of chromosome sets in the endosperm (Wangenheim 1962, 1967). However, none of these hypotheses explains all the observed cases of seed failure.

Recently we have made an extensive diallel cross of a series of polyploid species in Avena, and observed many interesting results. Almost all the data are well interpreted by an advanced hypothesis of an opinion of Kihara and Nishiyama (1932).

\section{Materials and methods}

Ten species of Avena were used in the present study:

1 Present address: 18 Hazamacho, Shugakuin, Sakyoku, Kyoto, 606 Japan. 
1) Diploids $(2 \mathrm{n}=14) A$. strigosa and $A$. hirtula with $\mathrm{A}_{\mathrm{s}} \mathrm{A}_{\mathrm{s}}$ genomes; $A$. longiglumis with ${ }^{\mathrm{T}} \mathrm{A}_{1}{ }^{\mathrm{T}} \mathrm{A}_{1}, A$. pilosa with $\mathrm{C}_{\mathrm{p}} \mathrm{C}_{\mathrm{p}}$, and $A$. ventricosa with $\mathrm{C}_{\mathrm{v}} \mathrm{C}_{\mathrm{v}}$.

2) Tetraploids $(2 \mathrm{n}=28) A$. barbata with $\mathrm{A}_{\mathrm{s}} \mathrm{A}_{\mathrm{s}} \mathrm{BB}$, and $A$. magna with AACC (or AADD).

3) Hexaploids $(2 \mathrm{n}=42)$ A. fatua, A. sativa cv. Aurora and A. sterilis var. maxima with AACCDD.

Plants were grown under natural conditions in pots. Crossing was carried our for 8 successive years, 1969-1976. Five to ten primary florets were emasculated per panicle one or two days before anthesis, and the remaining florets were removed. Two days later stigmas were carefully dusted with fresh spores of pollen parents which were collected just before anthesis. Seed germination was usually tested in petri-dishes at $20 \pm 0.5^{\circ} \mathrm{C}$ in an incubator.

\section{Results}

Many reciprocal crosses between ten polyploid species were successfully made. However, in four diploid crosses $A$. ventricosa and $A$. longiglumis $q \times A$. pilosa $\delta$, and in $A$. longiglumis and $A$. hirtula $+\times A$. ventricosa $\hat{\delta}$, no hybrid seed was obtained, while their reciprocals easily set either viable or inviable kernels. The frequency of seed set varied widely in different cross combinations but it is not particularly discussed in this paper. Table 1 represents results of representative crosses, especially to show seed set, relation between seed development and germination, and seed length.

Pollinated florets were carefully observed at maturity and grouped into fertilized or unfertilized ovaries by size, especially the length and plumpness of seeds. The length of probably unfertilized ovaries varied from about 0.5 or 1.0 to $2.5 \mathrm{~mm}$ in diploid species and $A$. barbata (4x), and from about 1.5 or 2.0 to $3.5 \mathrm{~mm}$ in $A$. magna $(4 \mathrm{x})$ and hexaploid species. In certain crosses ovaries of intermediate lengths were occasionally found which had little or no contents and were usually ungerminable. These were arbitrarily classified as unfertilized ovaries.

Hybrid kernels which often differed in development or shape and size from those of the maternal selfed plant were classified into three types; normal (designated $D$ ), empty (E) and small (Rd). The kernel development of the D type was similar to or only slightly less than that of the maternal parent. The E-type kernels practically consisted of only a large empty shrivelled pericarp at maturity. After pollination the ovary soon grew as large as that of the maternal selfed plant, but then the embryo and endosperm degenerated. The Rd-type kernels showed a reduced rate of endosperm or seed development, and sometimes were indistinguishable from unfertilized ovaries. They were small, slender or flat, fully or partly filled, and either viable or often inviable.

D-type kernels usually germinated very well, but remarkably none germinated in $A$. strigosa $(2 \mathrm{x}) \circ \times$ A. longiglumis $(2 \mathrm{x}) \delta$, and $A$. longiglumis $(2 \mathrm{x})$ 우 $\times A$. sativa (6x) or $A$. fatua (6x) $f$ while those from the reciprocals were germinable. Detailed observations of the former showed that only a basal portion of the kernel became abnormally slender and terribly shrunken, indicating the probable absence of an 
embryo. Presumably the embryo and its adjacent endosperm had disintegrated, leaving the well developed endosperm in the other regions. If $A$. sterilis was used instead of $A$. sativa or $A$. fatua typical empty kernels were produced, though the kernels from these crosses have the same genome constitution. The formation of such embryoless kernels is very interesting and is discussed later.

Table 1. Relationship between the development and germination of kernels from certain reciprocal interspecific crosses of Avena

\begin{tabular}{|c|c|c|c|c|c|c|c|c|}
\hline \multirow{2}{*}{ q } & \multirow{2}{*}{$\begin{array}{l}\text { Floret } \\
\text { poll. }\end{array}$} & \multicolumn{2}{|c|}{ Seed set } & vs & \multicolumn{3}{|c|}{ germination } & \multirow{2}{*}{$\begin{array}{l}\text { Seed } \\
\text { length, } \mathrm{mm}\end{array}$} \\
\hline & & \multicolumn{2}{|c|}{ Typ. D } & \multicolumn{2}{|c|}{ Typ. Rd } & \multicolumn{2}{|c|}{ Typ. E } & \\
\hline A. hirt. $\times$ strig. & 6 & 5 & 5 & & & & & $4-4.5$ \\
\hline A. pilo. $\times$ hirt. & 53 & & & & & 15 & 0 & $5-6.5$ \\
\hline Recip. & 40 & & & 14 & 2 & & & $3-4$ \\
\hline A. strig. $\times$ pilo. & 5 & & & 4 & 4 & & & $3.5-4$ \\
\hline A. vent, $\times$ hirt. & 82 & (7) & 0 & & & 5 & 0 & $4.5-5.5$ \\
\hline A. long. $\times$ strig. & 27 & 14 & 14 & & & & & $7-8$ \\
\hline Recip. & 35 & $23^{* *}$ & 0 & & & & & $6-7$ \\
\hline A. strig. $\times$ magna & 15 & 9 & 9 & & & & & $5.5-6.5$ \\
\hline Recip. & 14 & 9 & 5 & $5^{*}$ & 0 & & & $7.2-7.8,4.5-6.5^{*}$ \\
\hline A. pilo. $\times$ magna & 11 & & & & & 10 & 0 & $5-6$ \\
\hline Recip. & 83 & & & 23 & 0 & & & $4-5$ \\
\hline A. pilo. $\times$ barba. & 12 & & & & & 5 & 0 & $5-5.1$ \\
\hline Recip & 27 & & & 8 & 0 & & & $3-5$ \\
\hline A. vent $\times$ barba. & 47 & & & & & 12 & 0 & $4.5-6.5$ \\
\hline Recip. & 43 & & & 20 & 0 & & & $3-4.1$ \\
\hline A. long. $\times$ barba. & 14 & 8 & 4 & & & & & $8.5-9.5$ \\
\hline Recip. & 35 & 9 & 6 & & & & & $5.7-6.5$ \\
\hline A. hirt. $\times$ steri. & 12 & & & & & 6 & 0 & $3.5-5$ \\
\hline Recip. & 57 & & & 42 & 0 & & & $3-3.5$ \\
\hline A. pilo. $\times$ sativa & 34 & & & & & 18 & 0 & $3.5-4.5$ \\
\hline Recip. & 30 & & & 26 & 0 & & & $3.5-4$ \\
\hline A. long. $\times$ sativa & 14 & $11^{* *}$ & 0 & & & & & $7-7.5$ \\
\hline Recip. & 19 & 9 & 9 & $2^{*}$ & 0 & & & $6.5-7.5,3.5-4^{*}$ \\
\hline A. long. $\times$ steri. & 23 & & & & & 8 & 0 & $6.5-7.5$ \\
\hline Recip. & 44 & 10 & 9 & $24^{*}$ & 2 & & & $6.5-8,4-5.5^{*}$ \\
\hline A. magna $\times$ sativa & 37 & & & & & 21 & 0 & $7.5-10$ \\
\hline Recip. & 8 & & & 6 & 6 & & & $6.5-7$ \\
\hline A. magna $\times$ steri. & 52 & & & & & 38 & 0 & $7.5-10$ \\
\hline Recip. & 38 & & & 141 & 13 & & & $5.5-7$ \\
\hline & & & & $8^{*}$ & 0 & & & $4.5-5^{*}$ \\
\hline A. barba. $\times$ steri. & 6 & 6 & 6 & & & & & $5.5-6.5$ \\
\hline
\end{tabular}

* Intermediate development of kernels, ** Embryoless kernels.

Two kinds of kernels were found within the Rd-type; one was nearly plump and viable, and the other was very small and inviable with more or less contents as in $A$. sterilis crossed with $A$. magna pollen. In $A$. magna $+\times A$. strigosa ${ }^{\star}$ as well as $A$. sativa $q$ and $A$. sterilis $q \times A$. longiglumis $\hat{~}$, both kinds of $\mathrm{D}$ - and $\mathrm{Rd}-$ type kernels were found. The former showed good germination unlike the latter. From several evidences the latter may be caused by the failure of full growth, probably affected by environmental conditions. 
In the crossing technique each previously emasculated floret was dusted with ripe pollen collected only just before natural anthesis of male parents. Accordingly only a limited number of florets was pollinated in a day, especially when pollen parents had the same flowering time. However, it seems to result in better seed set than that reported by several workers (Holden 1966). The correct time of daily flowering is estimated after consideration of flowering time proper to each species and meteorological conditions, especially temperature. According to Nishiyama (1970), anthesis of $A$. longiglumis is about 4:30 a. m. in the darkness of early morning. However, when $A$. longiglumis was moved from the field under a light, fluorescent 30 watt, at about $8 \mathrm{p} . \mathrm{m}$. anthesis began within a few minutes. Anthers spread abundant ripe pollen suitable for artificial crossing although it was about 9 hours before natural anthesis. This observation supports Nishiyama's suggestion that its pollen could reach maturity in the daytime of the day before natural anthesis (Nishiyama 1970).

Summarizing the present data with those of Nishiyama (1929) and Kihara and Nishiyama (1932), a relationship between the development and germination of hybrid kernels is presented in Fig. 1. Three intermediate types of kernels, D(E), $E(D)$ and $R d(D)$, are newly distinguished from the three types, D, E and Rd, mentioned above. The type $D(E)$ indicates the subnormal such as embryoless kernels. The type $E(D)$ is close to the type $E$, but the endosperm is only partly filled. The type $\mathrm{Rd}(\mathrm{D})$ is of intermediate development between type $\mathrm{Rd}$ and $\mathrm{D}$. Viability of hybrid grains is designated as + , regardless of germination percentage, and inviability as - No difference in crossing behavior is usually observed in two diploid A. strigosa and A. hirtuls, and also in hexaploid A. fatua and A. sativa. While in certain cross combinations they show a slight but significant difference as separately recorded in Fig. 1. Further comparative inspections are made in detail on a relation between the seed development and cross combinations of parents below.

i) Crosses between species with the same chromosome number.

All $4 x \times 4 x$ and $6 x \times 6 x$ reciprocal crosses produce normal plump kernels (type $\mathrm{D}+$ ), while $2 \mathrm{x} \times 2 \mathrm{x}$ shows markedly different results depending upon the combination of parental species. As noted above, the total failure of cross-fertilization occurred in four cases of this group (marked with 0 in Fig. 1), but their reciprocals set kernels of type $\mathrm{D}+$ or $\mathrm{E}-$. When $A$. strigosa and $A$. hirtula (both $\mathrm{A}_{\mathrm{s}} \mathrm{A}_{\mathrm{s}}$ ) are crossed with A. longiglumis pollen, the former produces subnormal kernels and the latter wrinkled ones with little or no content. Both of them are inviable. While the reciprocal, A. longiglumis $\times A$. strigosa, sets normal plump kernels. In $A$, pilosa and $A$. ventricosa crossed with $A$. hirtula or $A$. strigosa pollen all kernels showed the E type, except both kinds of types $\mathrm{E}$ and $\mathrm{D}$ in $A$. ventricosa $9 \times A$. hirtuls $\delta$ although an occurrence of the latter can be questioned. $A$. strigosa and $A$. hirtula $q \times$ $A$, pilosa $\delta$ set kernels of the $\mathrm{Rd}+$ type, although those of the latter were barely germinable.

ii) $2 \times \times 4 \mathrm{x}$

The triploid cross also shows a great variability in seed development. The reciprocal $A$. longiglumis $(2 \mathrm{x}) \times A$. barbata $(4 \mathrm{x})$, and $\times A$. magna $(4 \mathrm{x})$ set $\mathrm{D}+$ type 
kernels. A. strigosa (2x) crossed with $A$. magna (4x) in any direction also produced normal kernels. However, when $A$. barbata $(4 \mathrm{x})$ was used as a pollen parent instead of $A$. magna (4x) it set kernels of typical type $\mathrm{E}-$. The reciprocal gave small plump kernels which germinated well (type $\mathrm{Rd}+$ ). The other crosses produced kernels of type $\mathrm{E}-$, and the reciprocals gave inviable small ones with little or no content (type Rd-).

\begin{tabular}{|c|c|c|c|c|c|c|c|c|c|c|}
\hline$f \quad c$ & $\sigma^{7}$ & $A s^{1,2}$ & $C_{p}$ & $C_{v}$ & ${ }^{\top} A_{1}$ & $A C$ & $A_{s} B$ & $\mathrm{ACD}^{3,4}$ & $A C D$ & CD \\
\hline $\begin{array}{l}\text { A.hirtula } \\
\text { A.strigosa }\end{array}$ & As & $D+$ & $R d+$ & 0 & $\mathrm{E}^{\mathrm{D}} \frac{1}{\mathrm{E}}$ & $D+2$ & $E-$ & $E 2$ & & \\
\hline A. pilosa & $\mathrm{Cp}$ & $E \perp$ & $D+$ & $D+$ & $E-$ & $E-$ & $E$ - & $E 3$ & & - \\
\hline $\begin{array}{l}\text { A.ventri - } \\
\text { cosa }\end{array}$ & $C_{v}$ & $E-$ & 0 & $D+$ & $E-$ & $E$ - & $E-$ & E 3 & & - \\
\hline $\begin{array}{c}\text { A. longig - } \\
\text { lumis }\end{array}$ & ${ }^{\top} \mathrm{Al}$ & $D t^{2}$ & 0 & 0 & $D+$ & $D+$ & $D+$ & $D(E)-$ & & - \\
\hline A.magna & $A C$ & $D+2$ & $R d$ - & Rd - & & $D+$ & & \begin{tabular}{|l}
$E(D)$ \\
$E$
\end{tabular} & & - \\
\hline A.barbata & $A_{s} B$ & $R_{d}+$ & $R_{d}-$ & $R_{d}-$ & $D+$ & $D+$ & $D+$ & $0+$ & $D$ & + \\
\hline $\begin{array}{l}\text { A.sativa } \\
\text { A.fatua }\end{array}$ & $A C D$ & $\begin{array}{l}R_{d}+\frac{2}{2} \\
R_{d}+{ }_{2}\end{array}$ & $\mathrm{Rd}_{\mathrm{S}}-3$ & 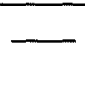 & $D+$ & $\operatorname{Rd}_{d}(D)_{+}^{3}$ & $D+$ & $D+$ & & + \\
\hline A.sterilis & $A C D$ & Rd - & Rd - & $R_{d}-$ & $\frac{\mathrm{D}+}{\mathrm{Rd}_{+}+}$ & $R_{d}(D)_{+}$ & $D+$ & $D+$ & $D$ & + \\
\hline
\end{tabular}

Fig. 1. Relationship between the development and germination of hybrid kernels in a diallel cross

o No fertilization of Avena species.

D Normal development of kernels

E Empty-shrivelled kernels

Rd Reduced development of kernels

D(E) Subnormal kernels, e.g. embryoless kernels

E(D) Type E kernels but partly filled with content

+ Germinable

- Inviable

Numeral superscripts, 1-4, indicate one of the parents used in the cross.

iii) $2 \mathrm{x} \times 6 \mathrm{x}$

In general the cross $2 \mathrm{x} q \times 6 \mathrm{x} \delta$ gave empty, and very shrivelled kernels, except for A. longiglumis ( $2 \mathrm{x})$. The reciprocal showed very poor development of kernels, most of them being difficult to germinate. When $A$. fatua was used as the maternal parent kernels were highly germinable (Kihara and Nishiyama 1932). It is very interesting that $A$. longiglumis showed a critical response to mating with hexaploid species, i. e., it produced plump kernels without embryos when pollinated with $A$. fatua or $A$. sativa, but set empty kernels when pollinated with $A$. sterilis. In the reciprocals the seed development was usually normal, but sometimes more or less inhibited. 
iv) $4 \mathrm{x} \times 6 \mathrm{x}$

In reciprocal $A$. barbata $(4 \mathrm{x}) \times$ three hexaploid species there were found almost normal kernels. A. magna $(4 \mathrm{x})$ produced empty and semi-empty kernels when crossed with $A$. fatua or $A$. sterilis and $A$. sativa, respectively. The reciprocals always set plump kernels which were a little smaller in size $(\operatorname{Rd}(D)+)$ than normals.

\section{Discussion}

Since the 1930's differences in seed development in reciprocal interspecific crosses have interested many workers. Similar phenomena have often been found in crosses between parents, differing in chromosome number or only in genome constitution, and all possible combinations of success $(S)$ and failure(F) in reciprocal $2 \mathrm{x} \times 4 \mathrm{x}$ crosses have been shown as follows;

$\begin{array}{lllllrl}\circ & & \delta & \text { I } & \text { II } & \text { III } & \text { IV } \\ 2 \mathrm{x} & \times & 4 \mathrm{x} & \mathrm{S} & \mathrm{F} & \mathrm{S} & \mathrm{F} \\ 4 \mathrm{x} & \times & 2 \mathrm{x} & \mathrm{S} & \mathrm{S} & \mathrm{F} & \mathrm{F}\end{array}$

Some examples refered to:

I. Beta vulgaris*, Triticum (Einkorn, $2 \mathrm{x}$ - Emmer, 4x)

II. Raphanus sativus*, Avena strigosa, $2 \mathrm{x}-$ A. barbata, $4 \mathrm{x}$

III. Primula veris, $2 \mathrm{x}-P$. elatior (autotetraploid)

IV. Primula elatior*, Galeopsis pubescens*

* Crosses between these diploid species and their autotetraploids.

Types II and IV are most frequently found, and especially in the latter occasional unexpected diploids or tetraploids are observed besides a few triploid hybrids (Gairdner and Darlington 1931, etc.).

Modification of the normal chromosome-number ratio $(2: 3: 2)$ in the three tissues embryo: endosperm: material tissue has been supported as an important explanation of the failure of hydridization by some authors (Håkansson 1952, 1953, 1956, Håkansson and Ellerström 1950, etc.). However, it is difficult to explain even the results of the present $2 x-4 x$ hybridization given above. Valentine (1956) stated that the genetic value (genetical potentialities of the gamete or of the tissues of the parents, Valentine and Woodell 1963) may be controlled by several unlinked genes of additive effect, and proposed a ratio of genetic value( $R$ ) of endosperm to maternal tissue in his study. In all selfed species $R$ is always 1.5 , which indicates the normal development of seeds. When $R$ is less than 1.5 small and poorly developed seeds are expected. When $R$ is greater than 1.5 seeds may be normal in size but abortive, or almost empty at maturity in the extreme case. It regrets that the hypothesis does not answer the question of what is the nature of genetic value on which it is based.

In Medicago sativa which shows partial self-incompatibility Brink and Cooper $(1939,1940)$ noted that the inner integument of nucellus shows unusual hyperplasia and the chalazal pocket is occluded in abortive seeds. Similar abnormalities were found in incompatible crosses of Nicotiana and Lycopersicon (Cooper and Brink 1940, 1945). They suggested that the maternal tissue gains an advantage for nutrient 
competition over the endosperm in the hybrids which results in its overgrowth but in death from starvation of the endosperm and embryo. They termed this type of seed failure 'somatoplastic sterility' (Brink and Cooper 1939). However, in hybrids between Hordeum and Secale, and between Elymus and Agropyron, hyperplasitic growth was not found in the maternal tissue but in the antipodals (Brink and Cooper 1944, Beaudry 1951).

The above mentioned hypotheses all share the basic idea that hybridization may cause a nutritional unbalance leading arrested development of seeds by altering the chromosome relations or by genome substitutions.

Kihara and Nishiyama (1932) found a remarkable difference in the morphology and embryology of kernels from reciprocal crosses between Avena strigosa ( $2 \mathrm{x}$ ) and A. fatua (6x). The most important embryological abnormalities were as follows:

A. strigosa $q \times A$. fatua of showed rapid growth of the nuclear endosperm, mitotic irregularities and giant masses of chromatin or micro-nuclei at $48 \mathrm{hr}$; degeneration of nuclear endosperm at $72 \mathrm{hr}$; and large, shrivelled, inviable kernels at maturity.

A. fatua $q \times A$. strigosa $\delta$ showed slow growth of the nuclear endosperm at $24 \mathrm{hr}$; poor growth of endosperm, cellular endosperm near the embryo as early as $48 \mathrm{hr}$, compared with at $72 \mathrm{hr}$ in both parents; endosperm near the embryo almost digested at $72 \mathrm{hr}$; endosperm near chalazal parts or antipodals still growing later than $72 \mathrm{hr}$; and small kernels partly filled, and partly germinable at maturity.

The development of hybrid embryos indicated only a difference in growth rate in the reciprocals. Kihara and Nishiyama (1932) have tried to explain their data by an inharmonious interaction between male and female nuclei at double fertilization. When the union of gametic nuclei occurs, the male nuclei activate the egg and polar nuclei, and initiate mitotic division associated with an increase of cytoplasm. The activating strength of $A$. fatua is expected to be three times as strong as that of $A$. strigosa, being an additive effect in proportion to chromosome number. Studies of interspecific crosses between Triticum species with different chromosome numbers supported this hypothesis (Wakakuwa 1934). Moreover, it fitted the results for reciprocal diploid $\times$ autotetraploid hybrids of Raphanus, Citrullus, Brassica and Capsicum (Nishiyama et al. 1952-1954, 1966).

Cooper and Brink (1940, 1944, 1945), Woodell (1960) and Valentine and Woodell (1963) have made good critical reviews of this subject and therefore we shall go no further in detail in this paper. Woodell (1960) stated that no worker has given a general rule covering all cases. However, Beaudry (1951) and Woodell (1960) consider the activating stimulus of male nuclei as an important cause of hybrid seed failure.

Before considering the present data we wish to outline some botanical aspects of our ideas concerning the hypothesis of polar-nuclei activation. In angiosperms developmental patterns of seeds vary widely in different groups of plants, but the principal process invariably consists of the following three events; 1) double fertilization, 2) initiation of mitotic division of the fertilized egg and primary endosperm nucleus, associated with an increase of cytoplasmic endosperm, and 3) differentiation of the embryo and endosperm followed by physiological and struc- 
tural changes of several tissues of the ovule. In most plants the egg cell and polar nuclei remain in a state of suspended development, which proceeds only when the union of gametic nuclei occurs. Thus, meristematic activity of the egg and polar nuclei is presumably brought about by the male nuclei, or rather by the interaction between them. In intraspecific pollination the egg and polar nuclei can be harmoniously activated by the male nuclei, and the seed develops normally. However, the balanced interaction may be disturbed sometimes in distant crosses, probably because of hyper- or hypoactivating action of the male nucleus. Such unbalanced activation may first cause disturbance of the physiology of embryogenesis, followed by histological abnormalities in the endosperm, embryo and maternal tissues.

Table 2 compares the main embryological events in seed failure of reciprocal Brassica chinensis $(\mathbf{n}=10) \times B$. pekinensis (autotetraploid, $\mathbf{n}=20$ ). Both species have the same genome constitution (Nishiyama and Inomata 1966).

Table 2. Comparison of main differences in the development of embryo and endosperm of reciprocal Brassica chinensis $(2 \mathrm{x}=20) \times B$. pekinensis(autotetraploid, $4 x=40$ ) and the parents (Nishiyama and Inomata 1966)

\begin{tabular}{|c|c|c|c|c|c|}
\hline & \multicolumn{5}{|c|}{ Days after pollination } \\
\hline & 6 & 9 & 12 & 15 & $18-21$ \\
\hline \multicolumn{6}{|l|}{ Parents } \\
\hline Embryo & 4.4 or 4 cells* & globular & heart-shape & torpedo & upturned U \\
\hline Endosperm & nuclear & $\longrightarrow$ & $\begin{array}{l}\text { slightly } \\
\text { cellular }\end{array}$ & cellular & digested \\
\hline \multicolumn{6}{|l|}{$2 \mathrm{x} \times 4 \mathrm{x}$} \\
\hline Embryo & 5.4 cells* & globular & $\longrightarrow$ & globular-flat top & $\longrightarrow$ \\
\hline Endosperm & nuclear & $\begin{array}{l}\stackrel{\longrightarrow}{ } \text { abnormally } \\
\text { vacuolated }\end{array}$ & $\begin{array}{r}\longrightarrow \\
\text { begin to } \\
\text { degenerate }\end{array}$ & $\begin{array}{l}\longrightarrow, \\
\text { degenerating, } \\
\text { abnormal } \\
\text { nuclei }\end{array}$ & disintegrating \\
\hline \multicolumn{6}{|l|}{$4 x \times 2 x$} \\
\hline Embryo & 4.5 cells* & globular & $\longrightarrow$ & $\longrightarrow$ & disintegrating \\
\hline Endosperm & $\begin{array}{l}\text { nuclear or } \\
\text { slightly } \\
\text { cellular }\end{array}$ & $\begin{array}{c}\text { cellular, } \\
\text { poor growth }\end{array}$ & $\begin{array}{r}\text { begin to } \\
\text { degenerate }\end{array}$ & disintegrating & $\longrightarrow$ \\
\hline
\end{tabular}

In both Brassica and Avena the first signs of embryological abnormality in abortive seeds appear in the endosperm, and the endosperm in the vicinity of the embryo is probably more sensitive to the effect of hybridization than is any other part of the ovule. The symptoms of seed failure are essentially and closely similar in different species, though minor differences depend on the divergence of plant characteristics. There is considerable evidence on this point.

Why is the endosperm so sensitive to a foreign sperm? It is noteworthy that the only basic difference between embryo and endosperm cells is in their chromosome constitutions, i. e. the former is $2 \mathrm{n}$ usually, whereas the latter is $3 \mathrm{n}$. The strength of the activating action versus the reaction between male and female gametes is arbitrarily given the term 'activating value(AV) versus response value(RV)'. The activating value peculiar to each species is probably governed by a functional gene 
or genes, named 'activator'. The degree of activation of the egg nucleus, and the polar nuclei, can be expressed by an activation index(AI) which is generally indicated by a ratio of activating value of a male nucleus: response value of an egg or two polar nuclei, i. e. $\mathrm{AV} / \mathrm{RV}=1$ (or $100 \%$ ) in the former and $\mathrm{AV} / 2 \mathrm{RV}=0.5($ or $50 \%$ ) in the latter, because $A V=R V$ in a selfed plant. Why the egg nucleus and polar nuclei are differently activated in the same ovule is unknown. It is suggested that it is a biological mechanism in which the growing endosperm is more sensitive to the unusual activating action of alien pollen than is the developing embryo. This view is supported by results obtained in many embryological investigations involving the successful artificial culture of excised embryos from young hybrid seeds, which normally abort. Mitosis in the egg and endosperm is initiated by the activator depending on the activation index, otherwise they remain suspended. Abnormal endosperm development may be caused by disturbed activation index. The greater the deviation in the plus or the minus direction from the standard 50 per cent, then the greater the abnormality to overgrowth or to inhibition of the seed formation. If the endosperm fails to develop normally the embryo suffers. It may abort or remain in a rudimentary organ so that the nutrients transfered through the maternal tissues are no longer needed for the arrested endosperm. The maternal tissue may become over-enriched with the excessive nutrient and this may further disturb the general balance of metabolism in the ovule and result in histological abnormalities. As noted by many authors embryological data are so diverse that no generalization about the patterns of seed abortion can be made. This suggests that the manifestation of minor abnormalities is often secondarily affected by characteristics of the species.

The present crossing results for Avena fit quite well with the concept of the activation hypothesis. Relative activating values for the species used were estimated by the degree of abnormal development of hybrid seeds. If a value of 1 was adopted for $A$. strigosa $\left(\mathrm{n}=7\right.$, genome $\left.\mathrm{A}_{\mathrm{s}}\right)$ as the standard, relatively 0.5 for $A$. pilosa $(\mathrm{n}=7$, $\mathrm{C}_{\mathrm{p}}$ ), 1.7 for $A$. longiglumis $\left(\mathrm{n}=7,{ }^{\mathrm{T}} \mathrm{A}_{1}\right), 1.9$ for $A$. barbata $\left(\mathrm{n}=14, \mathrm{~A}_{\mathrm{s}} \mathrm{B}\right), 3$ for $A$. sterilis $(\mathrm{n}=21, \mathrm{ACD}$ ), etc. (Table 3). Table 3 lists relationships between the seed development (including germination), and the activation index $(\%)$ of the polar nuclei in 74 reciprocal crosses. The indices range from 7 to 375 per cent, compared with a standard of 50 per cent in $A$. strigosa. Activation indices grouped into four types and five intermediate types of kernel development are distributed as follows:
1. $\mathrm{Rd}-$
$7-16.7$ (10 crosses)
2. $R d+$
17.9 ( 1 cross)
$\mathrm{Rd}+,-$
$17.2,24-28$ ( 5 crosses $)$
$\operatorname{Rd}(\mathrm{D})$
$27-28.6$ ( 2 crosses)
$\mathrm{D}, \mathrm{Rd}+$
28.3 ( 1 cross)
3. $\mathrm{D}+$
29.3 - 80 ( 28 crosses)
$\mathrm{D}(\mathrm{E})-$
$E(D)-$
$82-85$ ( 3 crosses)
87.5 ( 1 cross)
4. E-
88.2 - 375 ( 23 crosses)

There is a close agreement between seed development and activation index, 
Table 3. Relationship between the kernel development and activation index(AI) of polar nuclei in interspecific hybridization of Avena

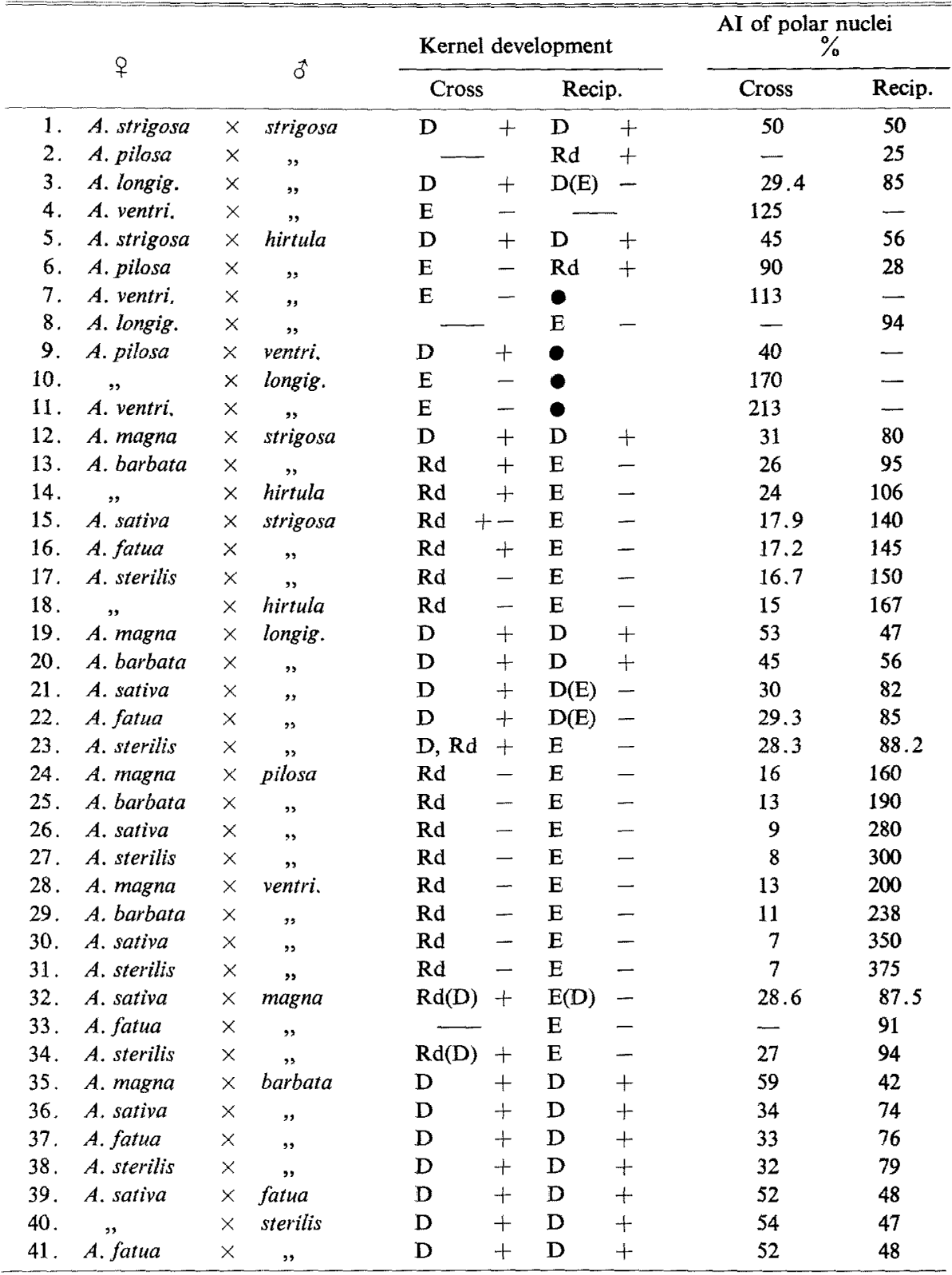

Activating values of the species
A. ventricosa 0.4
A. pilosa
0.5
A. hirtula
0.9
A. strigosa 1
A. longiglumis
1.7
A. magna
1.6
A. barbata $\quad 1.9$
A. sativa
2.8
A. fatua
2.9
A. sterilis
3

No kernel was obtained. 
except for a slight disagreement in just two or three crosses, lying on the boundary between the $\mathrm{Rd}+$ and $\mathrm{Rd}$ - or D+ types. All three hexaploids, A. sterilis, A. fatua and $A$. sativa, crossed with $A$. strigosa $(2 \mathrm{x})$ set poor kernels whose germination seemed to be variable. This may reflect their activation indices $(16.7,17.2$ and 17.9 per cent) which fall on the border between the $\mathrm{Rd}+$ and $\mathrm{Rd}-$ types. Perhaps they are apt to be affected by environmental conditions or an additional genetic factor, (e. g. a modifier if present). The occasional unexpected development of kernels in certain cross combinations can be similarly interpreted. For example, in addition to normal kernels, hexaploids $\times A$. longiglumis $(2 x)$ sometimes gave partly filled small kernels, which showed a low germination. In certain cases there were also found inviable intermediates between unfertilized ovaries and Rd-type kernels.

The activation index(AI) series can be simply illustrated in the form of a diagram, dividing $<20,20-30,30-80$ and $>80$ per cent in round numbers which correspond to the $\mathrm{Rd}-, \mathrm{Rd}+, \mathrm{D}+$ and $\mathrm{E}-$ - types, respectively (Fig. 2). Intermediate types are found on the boundaries between them. Thus, in general, when the activating value(AV) of the male parent is $<40$ or $>160$ per cent that of the female parent

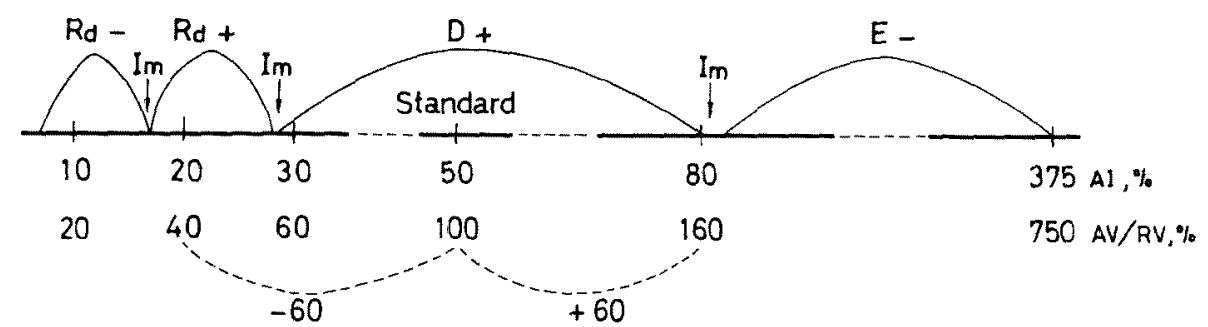

Fig. 2. Diagramatic illustration of relationships between the kernel development and the activation index $(\%)$ of the polar nuclei $(\mathrm{AI}=\mathrm{AV} / 2 \mathrm{RV} \times 100)$, with an appendix of percentage ratios of the activating value of the male parent to that of the female parent $(\mathrm{AV} \gamma / \mathrm{RV}(=\mathrm{AV})$ 우 $\times 100)$. Im shows intermediate types of the kernel development.

which is equal to the AI of the embryo (Fig. 2), they are cross-incompatible. Moreover the cross is compatible when the activating value of the male parent falls within a range of \pm 60 per cent of that of the female parent. In these wide crosses the harmfulness of hybridization is primarily effective to the endosperm and not the embryo. It is important to note here that Thomas (1970) successfully obtained the hybrid $A$. ventricosa $(2 \mathrm{x}) \times A$. saiva $(6 \mathrm{x})$ by artificial culture of excised embryos from young seeds wherein the AI of the egg nucleus and polar nuclei is as high as 700 and 350 per cent, respectively.

The hypothesis may apply to many other cases of seed failure in interspecific crosses of higher plants. According to Cooper and Brink (1945) the cross-incompatibility between Lycopersicon species and its autotetraploid was hardly explained by the hypothesis of the somatoplastic sterility or the chromosome ratio of three tissues. We would like briefly to refer to the extent to which seed formation is successful or failure in crosses between these plants. After inspecting the crossing data, following activating values were arbitrarily chosen for the haploid chromosome sets of the three parents; 1 for L. pimpinellifolium, 2 for its autotetraploid, and 1.8 for $L$. pervianum. The symbols ' $\mathrm{x}$ ' and ' $\mathrm{x}_{\mathrm{p}}$ ' refer to the haploid set of $L$. pimpinel- 
lifolium and $L$. pervianum chromosomes, respectively. The relation between the activation index and hybrid-seed development is given as follows:

\begin{tabular}{lcccccc} 
Cross & $2 \mathrm{x} \times 4 \mathrm{x}$ & $2 \mathrm{x} \times 2 \mathrm{x}_{\mathrm{p}}$ & & $2 \mathrm{x} \times 2 \mathrm{x}$ & $4 \mathrm{x} \times 2 \mathrm{x}_{\mathrm{p}}$ & $4 \mathrm{x} \times 2 \mathrm{x}$ \\
Activation index $(\%)$ & 100 & 90 & & 50 & 45 & $\frac{25}{\text { inviable }}$ \\
\cline { 2 - 3 } & inviable & & viable &
\end{tabular}

In Lycopersicon both reciprocal $2 \mathrm{x} \times 4 \mathrm{x}$ crosses failed to yield viable plump seeds. As the activation index in $2 x \times 2 x_{p}$ is closer to that in $2 x \times 4 x$ than the standard in $2 x \times 2 x$ hybrid seeds should be abortive. For the same reson $4 x \times 2 x_{p}$ is successful, though $4 \times \times 2 \times$ fails.

Since the discovery of double fertilization in flowering plants by Navashin (1898) and Guignard (1899), the triple union of two polar nuclei with a male nucleus which give rise to a primary endosperm nucleus has remained a puzzling event in sexual reproduction. As discussed at length, it is suggested that the triple fusion can play an important role in sexual isolation by means of the defective development of endosperm when crosses between undesirable plant species occur. The isolation mechanism is only effective when both parents differ to a certain extent in their activating values, and it may be a gametophyte character governed by a genetic factor (or factors) which differentiated in the evolutionary pathway of plant species.

\section{Summary}

A diallel cross was made using ten polyploid species, $2 \mathrm{x}, 4 \mathrm{x}$, and $6 \mathrm{x}, \mathrm{x}=7$, in the genus Avena. In most crosses hybrid seeds were successfully obtained though the frequency of seed set varied greatly. The development of hybrid seeds differed widely between cross combinations, especially in reciprocal crosses. Hybrid seeds were classified into four types, 1) normal kernels, well developed and germinable (designated as $\mathrm{D}+$ ), 2) shrivelled-empty kernels which do not germinate $(\mathrm{E}-$ ), 3) small viable kernels ( $\mathrm{Rd}+$ ) and 4) small inviable kernels ( $\mathrm{Rd}-$ ). Some intermediate types were occasionally found.

The results are fairly well explained in terms of a hypothesis of polar-nuclei activation in which the strength of the activating action of the male nucleus, and the reaction of the female nucleus is expressed by terms 'activating value (AV)' and 'response value (RV)', respectively. The degree of seed failure is closely related to the difference between the activating and response values, expressed by the activation index, $\mathrm{AV} / 2 \mathrm{RV}$ (or $\times 100$ ) of the polar nuclei. In a selfed plant the activation index (AI) of the polar nuclei is $1 / 2=0.5$ (or $50 \%$ ), and this usually being the normal index results in the production of normal seeds. If AI deviates from 50 per cent the development of endosperm is often arrested or aborted.

Based on the degree of abnormality of hybrid kernels, activating values of the ten species are arbitrarily assigned from 0.4 in $A$. ventricosa $(2 \mathrm{x})$ to 3 in $A$. sterilis $(6 \mathrm{x})$ compared with 1 in $A$, strigosa $(2 \mathrm{x})$ as the standard. Among 74 reciprocal interspecific crosses the AI of the polar nuclei varied widely from 7 to 375 per cent. The distribution of these indices agrees closely with the grouping of the four kernel types. Thus, AI values of less than 20,20-30,30-80, and more than 80 per cent show the $\mathrm{Rd}-, \mathrm{Rd}+, \mathrm{D}+$ and $\mathrm{E}-$ kernel types, respectively. In other words, 
if the AV of the pollen parent is $>160$ or $<40$ per cent that of the maternal parent they are cross-incompatible. Thus in double fertilization of angiosperms the triple fusion of two polar nuclei with a secondary male nucleus is apparently a biological isolation mechanism and may be the most effective barrier to hybridization on occasion.

\section{Acknowledgments}

The authors wish to express their gratitude to Dr. H. Kihara, Director of Kihara Institute for Biological Research, for encouragement during the course of this study, and also to Professor C. D. Darlington, University of Oxford, England and Professor R. Riley, Plant Breeding Institute, Cambridge, England for their valuable advice in the preparation of the manuscript. The authors are indebted to Dr. M. Bennett, University of California, San Diego, U.S.A. for critical reading of the manuscript and helpful suggestions. Thanks are also due to Dr. T. Rajhathy, Canadian Department of Agriculture, Ottawa, Canada, who kindly supplied some wild Avena species which collected by him and his colleagues in the Mediterranean region.

\section{References}

Beaudry, J. R. 1951. Seed development following the mating Elymus virginicus L. $\times$ Agropyron repens (L.) Beauv. Genetics 36: 109-133.

Boyes, J. W. and Thompson, W. P. 1937. The development of the endosperm and embryo in reciprocal interspecific crosses in cereals. J. Genetics 34: 203-227.

Brink, R. A. and Cooper, D. C. 1939. Somatoplastic sterility in Medicago sativa. Science 90: 545-546.

- and - 1940. Double fertilization and development of the seed in angiosperms. Bot. Gaz. 102: $1-25$.

- and - 1944. The antipodals in relation to abnormal endosperm behavior in Hordeum jubatum $\times$ Secale cereale hybrid seeds. Genetics 29: 391-406.

Cooper, D. C. and Brink, R. A. 1940. Somatoplastic sterility as a cause of seed failure after interspecific hybridization. Genetics 25: 593-617.

- and - 1944. Collapse of the seed following the mating of Hordeum jubatum $\times$ Secale cereale. Genetics 29: 370-390.

- and - 1945. Seed collapse following the mating between diploid and tetraploid races of Lycopersicon pimpinellifolium. Genetics 30: 376-401.

Gairdner, A. E. 1926. Campanula persicifolia and its tetraploid form, 'Telham Beauty'. J. Genetics 16: $341-351$.

- and Darlington, C. D. 1931. Ring formation in diploid and polyploid Campanula persicifolia. Genetica 13: 113-150.

Guignard, L. 1899. Sur les anthérozoides et la double copulation chez les végétaux angiospermes. Compt. Rend. Acad. Sci., Paris 128: 864-871.

Håkansson, A. 1952. Seed development after $2 \mathrm{x}, 4 \mathrm{x}$ crosses in Galeopsis pubescens. Hereditas 38: $425-448$.

- 1953. Endosperm formation after $2 x, 4 x$ crosses in certain cereals, especially in Hordeum vulgare. Hereditas 39: 57-64.

- 1956. Seed development of Brassica oleracea and $B$. Rapa after certain reciprocal pollinations. Hereditas 42: 373-396.

- and Ellerström, S. 1950. Seed development after reciprocal crosses between diploid and tetraploid rye. Hereditas 36: 256-296. 
Holden, J. H. W. 1966. Species relationships in the Avenae. Chromosoma (Berl.) 20: $75-124$.

Howard, H. W. 1939. The size of seeds in diploid and autotetraploid Brassica oleracea L. J. Genetics 39: 325-340.

- 1947. Seed size in crosses between diploid and autotetraploid Nasturtium officinale and allotetraploid N. uniseriatum. J. Genetics 48: 111-.

Katayama, Y. 1933. Crossing experiments in certain cereals with special reference to different compatibility between the reciprocal crosses. Memoirs Coll. Agr., Kyoto Imp. Univ. 27: $1-75$.

Kihara, H. and Nishiyama, I. 1932. Different compatibility in reciprocal crosses of Ayena, with special reference to tetraploid hybrids between hexaploid and diploid species. Japan. J. Botany 6: 245-305.

Müntzing, A. 1930. Über Chromosomenvermehrung in Galeopsis-Kreuzungen und ihre phylogenetische Bedeutung. Hereditas 14: 153-172.

- 1933. Hybrid incompatibility and the origin of polyploidy. Hereditas 18: 33-56.

Navashin, S. 1898. Resultate einer Revision der Befruchtungsvorgänge bei Lilium martagon und Fritillaria tenella. Bull. Acad. St. Petersbourg 9, No. 4.

Nishiyama, I. 1929. The genetics and cytology of certain cereals I. Morphological and cytological studies on triploid, pentaploid and hexaploid Avena hybrids. Japan. J. Genetics 5: $1-48$.

- 1952. Polyploidy studies in the Brassiceae I. The seed development in reciprocal crosses between diploid and tetraploid Raphanus. Memoirs Res. Inst. Food-Sci., Kyoto Univ. 3: $1-7$.

-, Shimotsuma, M. and Yabuno, T. 1952. A comparative study on the development of polyploid seeds in watermelon. Rep. Kihara Inst. Biol. Res. (Seiken Zihô) 5 : 110-118,

- and Inamori, Y. 1953. Polyploidy studies in the Brassiceae III. Hybridization between diploid Brassica species $(2 \mathrm{n}=20)$ and their autotetraploids. Memoirs Res. Inst. Food-Sci., Kyoto Univ. 5: 1-13.

- and Karasawa, H, 1954. Somatoplastic sterility in reciprocal crosses between $2 \mathrm{x}-$ and $4 \mathrm{x}-$ plants in Capsicum. (Japanese with English summary). Japan. J. Breeding 3: 36-40.

- and Inomata, N. 1966. Embryological studies on cross-incompatibility between $2 \mathrm{x}$ and $4 \mathrm{x}$ in Brassica. Japan. J. Genetics 41:27-42.

- 1970. Four types of flowering time in Avena. Japan. J. Genetics 45: 399-409.

Stephens, S. G. 1942. Colchicine-induced polyploids in Gossypium I. An autotetraploid Asiatic cotton and certain of its hybrids with wild diploid species. J. Genetics 44: 272-295.

Thomas, H. 1970. Chromosome relationship between the cultivated oat, Avena sativa $(6 \mathrm{x})$ and A. ventricosa(2x). Can. J. Genet. Cytol. 12: 36 43.

Valentine, D. H. 1956. Studies in British Primulas V. The inheritance of seed compatibility. New Phytol. 55: 305-318.

- and Woodell, S. R. J. 1963. Studies in British Primulas X. Seed incompatibility in intraspecific and interspecific crosses at diploid and tetraploid levels. New Phytol. 62: 125143.

Wakakuwa, S. 1934. Embryological studies on the different seed-development in reciprocal interspecific crosses of wheat. Japan. J. Botany 7: 151-185.

Wangenheim, K. H. v. 1962. Zur Ursache der Abortion von Samenanlagen in Diploid-PolyploidKreuzungen II. Unterschiedliche Differenzierung von Endospermen mit gleichem Genom. Z. Vererbungslehre 93: 319-334.

- 1967. Entwicklungsphysiologische Untersuchungen über die Beteiligung nukleärer und extranukleärer Erbträger an der Phänogenese. Ber. Deut. Bot. Gesell. 80: 228-236.

Watkins, A. E, 1927. Genetic and cytological studies in wheat III. J. Genetics 18: 375-396.

- 1932. Hybrid sterility and incompatibility. J. Genetics 25: 125-162.

Woodell, S. R. J. 1960. Studies in British Primulas VIII. Development of seed from reciprocal crosses between $P$. vulgaris Huds. and $P$. elatior $(\mathrm{L}$.) Hill and between $P$. veris $\mathrm{L}$. and $P$. elatior (L.) Hill. New Phytol. 59: 314-325.

- and Valentine, D. H. 1961. Studies in British Primulas IX. Seed incompatibility in diploidautotetraploid crosses. New Phytol. 60: 282-294. 